\title{
Solar Silicon Array Performance in Generating a Ratio of Electrical Energy for Hercules Aircraft
}

\author{
Hamid Radmanesh ${ }^{1}$ \\ Hamid Mohammad Hossein ${ }^{2}$ \\ ${ }^{1}$ Associate Professor, Electrical Engineering Department, Shahid Sattari Aeronautical University of Science and \\ Technology, Tehran, Iran \\ Radmanesh@ssau.ac.ir \\ 2 Assistant Professor, Command and General Staff College of the Islamic Republic of Iran, Tehran, Iran \\ hmh.1343@yahoo.com
}

\begin{abstract}
:
This paper presents existent model for solar silicon cell and introduces different parts of Hercules electrical system which proposed cell is used for generating a ratio of electrical energy for Hercules. Then, novel electrical energy distribution system based on solar cell will be presented. This model will contributed in generating aircraft start-up power and act as backup electrical system boosting flight reliability. Moreover, considering different values for cell parameters, effect of selecting appropriate model and parameter on solar array performance will be evaluated. Next, the result of temperature on proposed model will be assessed considering maximum output power and total generated power by solar arrays.
\end{abstract}

Keywords: Modeling, Solar Array, Equivalent Circuit, Photovoltaic System, Hercules Aircraft.

Submission date : 06, Feb. , 2020

Conditional Acceptance date: 29, Sep. , 2020

Acceptance date : 04, Nov. 2020

Corresponding author : Hamid Radmanesh

Corresponding author's address: Shamshiri Street, Shahid Sattari Aeronautical University of Science and Technology, Tehran, Iran. Postal Code: 1387836111. 


\section{Introduction}

Generating electrical energy is an important base of a growing country considering its value. Meanwhile, accessing advanced technologies and utilizing green energies and reproducible systems developed significantly. Easy use of solar energy puts it in a preferable situation. Sun is the biggest energy supplier of the earth and the supplied energy is used in generating power via different modes. It will be more important considering the radiated solar energy is converted to electrical energy directly using photovoltaic systems. Production of solar cells and modules increased recently and reached more than $2500 \mathrm{MW}$ per year. In satellites the power subsystem is a photovoltaic type that gathers its energy and other power subsystems from a group of solar arrays. Solar arrays used in aerospace means, differs from conventional types in terms of type, used technology, coating material, electrical characteristics and mechanical structure. Satellite solar arrays and other spatial PVs are constructed from high efficiency materials. Applying the business plan method to forecast the five-year world production value and domestic production value of aerospace industry has been done in [1]. Advanced missions within the Air Force are investigating the use of flexible PV array systems. The rapidly-evolving technology of flexible thin film PV cells lends itself particularly well to a flexible array concept. Parallel incentives for development of flexible PV arrays are the possibilities of synergistic advantages for certain types of spacecraft, in particular the Solar Thermal Propulsion (STP) vehicle [2]. A low-cost high-efficiency DC-DC converter with maximum power point tracking (MPPT) functions, control, and Power Line Communications (PLC) has been studied in [3]. The performance of a PV array is affected by temperature, solar insulation, shading, and array configuration. Often, the PV arrays get shadowed by passing clouds, neighboring buildings and towers, trees, utility and telephone poles [4]. The situation is of particular interest in case of large PV installations such as those used in distributed power generation schemes [4]. Under partially shaded conditions, the PV characteristics get more complex with multiple peaks. Yet, it is very important to understand and predict them in order to extract the maximum possible power. This paper presents a MATLAB-based modeling and simulation scheme suitable for studying the $I-V$ and $P-V$ characteristics of a PV array under a non-uniform insulation due to partial shading [4], [7] and [11]. A novel topology for a photovoltaic (PV) DC-DC converter that can dramatically reduce the power rating and increase the efficiency of a PV system by analyzing PV module characteristics is proposed in [5]. PV stand-alone system requires a battery charger for energy storage. In [6] the modeling and controller design of the PV charger system implemented with the single-ended primary inductance converter (SEPIC). A transformer provides galvanic isolation and grounding of the PV array in a PV-fed grid connected inverter. Inclusion of the transformer, however, may increase the cost of the system. To overcome this drawback, a single-phase, single-stage (no extra converter for voltage boost or maximum power point tracking (MPPT)), doubly grounded, transformerless PV interface, based on the buck-boost principle, is presented in [8] and [9]. A control method for small utility connected large PV system to reduce frequency deviation using a minimal-order observer has been studied in [9]. A dynamical electrical array reconfiguration strategy on the PV generator of a gridconnected PV system based on a plant-oriented configuration in order to improve its energy production when the operating conditions of the solar panels are different is given in [10]. Sizing of PV generators is an important issue which might affect the PV system overall yield and performance ratio [12]. Fault analysis in solar PV arrays has been studied in [13-15]. Bypass diodes are frequently used to minimize the effects of shading on PV module power generation. However, the functionality and effectiveness of these diodes depends on proper installation of a module with respect to potential shade sources [16]. A new methodology for optimal design of transformer less PV inverters targeting a cost-effective deployment of grid connected PV systems has been given in [17] and [18]. Nowadays these cells are multilayer type "constructed from GaInp/GaAs/Ge" which some $\% 27$ efficiency samples have been used in spatial projects. Producing laboratory versions that reached $\% 50$ efficiency have been considered nowadays. Other suitable option is silicon cells which have been used in spatial missions years ago. Their efficiency has been tripled in recent 4 decades and reached \%24 in some cases. Other characteristic which discriminates spatial arrays from conventional types is high cost of their production. This paper investigates the PV application in Hercules aircraft for generation the electrical energy. The suggested scheme can be replaced with Auxiliary Power Unit (APU) with better performance and low cost. This paper has been organized as follow:

In section II, the concept of cell and array is discussed. Then, in section III, the MPPT concept and its equations is introduced. In section IV, the DC-DC converter in PV systems is discussed. In section V, the control strategy is introduced. So, the Hercules aircrafts electrical system is descried and MATLAB software is applied to investigate the operational behavior of the proposed system and related simulation results are analyzed. In the last section conclusion and references are given.

\section{Cell and Array Concept}

A solar array is produced by combination of multiple strings which stands in series or parallel. A string is a combination of several cells which there is a blanking diode at their endings in order to separate the specific strings from array. A group of these cells - which stand together based on factories default design in a peripheral protected layer in series or parallel and makes block structures of a PV generation unit is called panel or PV 
module [19]. A combination of these panels is called solar arrays as shown in Fig.1.

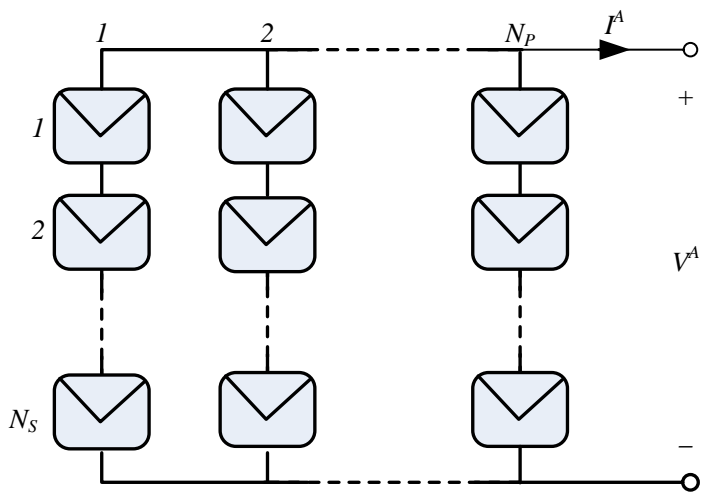

Fig. 1. Module configuration in a PV array

\subsection{Modeling Cell and Solar Array}

Usually, first step in simulation of power subsystem is simulation and modeling of solar arrays structure and performance. To fulfill that, first it is used to select an appropriate model for cell. The most complete model for single layer silicon cell is called "two diode equivalent circuits" and in case of choosing appropriate parameters for it, the model could represent actual behavior of cell accurately [19]. Aforesaid model is shown in Fig. 2.

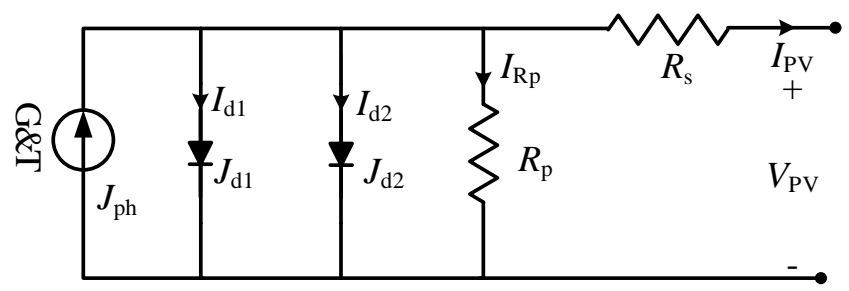

Fig. 2. Two diode equivalent circuit of single layer cell

Related equations of Fig. 2 are as bellow:

$$
\begin{aligned}
& J_{\text {cell }}=J_{p h}-J_{d 1}-J_{d 2}-\frac{\left(v_{\text {cell }}+R_{s} J_{\text {cell }}\right)}{R_{p}} \\
& J_{p h}(T, G)=\frac{G}{G_{0}} J_{p h}\left(T_{0}, G_{0}\right)\left(1+K_{p h}\left(T-T_{0}\right)\right) \\
& J_{d i}=J_{\text {sati }}\left(\exp \left(\frac{q\left(V_{\text {cell }}+R_{s} J_{\text {cell }}\right)}{n_{i} K T}\right)-1\right) \\
& J_{\text {sati }}(T)=J_{\text {sati }}\left(T_{0}\right)\left(\frac{T}{T_{0}}\right)^{\frac{2}{n i}} \exp \left(\frac{q}{n_{i} k} \frac{E_{g}(T)}{T}-\frac{E_{g}\left(T_{0}\right)}{T_{0}}\right) \\
& E_{g}(T)=1.17-4.37 \times \frac{10^{-4} T^{2}}{T+636} \\
& R_{s}(T, G)=R_{S}\left(T_{0}, G_{0}\right)+\varnothing_{G}\left(\frac{1}{G}-\frac{1}{G_{0}}\right)+V_{T}\left(T-T_{0}\right) \\
& R_{P}(T)=R_{P}\left(T_{0}\right) \exp \left(\psi_{T}\left(T-T_{0}\right)\right.
\end{aligned}
$$

In these equations $J_{\text {cell }}, V_{\text {cell }}, J_{\text {optical }}, J_{d 1}$ and $J_{s 2}$ represent current density, cell voltage, optical current density, darkness current density due to diffusion phenomena and darkness current density due to recombination phenomena, respectively. Specification of $J_{d 1}$ and $J_{d 2}$ requires determination of $J_{\text {sat } 1}$ and $J_{\text {sat } 2}$ which Eq.4 calculates it for $i=1,2$. Equation (4) needs $E_{r}$ band gap energy which can be obtained from Eq.5. For silicon $R_{S}$ and $R_{P}$ resistors could be represented as a function of $T$ temperature and $G$ radiation by Eqs.6 and 7. $R_{S}\left(T_{0}, G_{0}\right)$ and $R_{P}\left(T_{0}\right)$ could be achieved either by datasheets or standard methods presented in cells functional chart in nominal condition. Temperature factor $\phi_{T}, K_{p h}, V_{T}$ and $\psi_{G}$ depends on constructed technology and could be specified from datasheets. $K$ and $q$ represents Boltzmann coefficient and electrons charge. Ideal factor for diodes 1 and 2 is $n_{1}=1.3$ and $n_{2}=2$ considering their role. So in each time, receiving radiation power $(\mathrm{G})$ in $T$ temperature and for output load $\left(R_{L}\right)$ leads to current $I_{\text {cell }}=\frac{V_{\text {cell }}}{R_{L}}$ in cell.

The dominant feature of this method is that, having cell characteristic in a reference condition and a measurement in a random condition, it is possible to specify all parameters of the model. Having obtained cell module, next step is definition of array module. Although there are different methods for that, but if the same condition including temperature and radiation is considered for all cells of array, it is possible to define array model using Thevenin and Norton equivalent circuits. If a string including $N_{S}$ similar cell is assumed, it is well known that the optical current $\left(J_{p h}\right)$ and darkness current flowing in cells are same. Also it is clear that the series resistance of string is $N_{S}$ times of cells.

To calculate parallel resistance, it is possible to consider the sum of each source - $J_{p h}, J_{d 1}$ and $J_{d 2}$ - currents as a general source, and by converting it to Thevenin equivalent circuit, it is revealed that $R_{p}$ for each string would be $N_{S}$ times. Considering that in each branch, all of series diodes are the same, it is possible to assume that each branch includes only one diode if its voltage equals to $V_{\text {cell }}+R_{S} J_{\text {cell }}$. In implementation of equivalent circuit, the voltage of each group of diodes should be divided to $N_{S}$. When, $N_{p}$ same strings stand beside, the final equivalent circuit will include $N_{p}$ string equivalent circuit. Moreover, same $J_{p h}, J_{d 1}$ and $J_{d 2}$ can be assumed too. Because of using absolute values of currents instead of their density in equations related to arrays, it is possible to obtain all equations in terms of current by multiplying "optical currents density" and "darkness currents density" to $A_{\text {cell }}$ effective area of the cell. $A_{\text {cell }}$ is calculated by ignoring the areas covered by junctions and metal dactyls. Considering all of aforementioned notes, 
the main relationship between $V$ and $I$ could be written as Eq.8. "A" index refers to arrays quantity. Note that the dimension of parallel and series resistances is $\Omega$ unlike previous equations.

$$
\begin{aligned}
& I^{A}=I_{S C}^{A}-N_{A} I_{\text {sat } 1}\left(\exp \left(\frac{q\left(V^{A}+I_{P} R_{S}^{A}\right)}{N_{S} n_{1} K T}\right)-1\right) \\
& -N_{A} I_{\text {sat } 2}\left(\exp \left(\frac{q\left(V^{A}+I_{P} R_{S}^{A}\right)}{N_{S} n_{2} K T}\right)-1\right)-\frac{V_{A}+I_{A} R_{S}^{A}}{R_{A}}
\end{aligned}
$$

\subsection{Characteristic of Modelled Array}

In this paper the results of polycrystalline silicon solar arrays are used for defining cells and arrays models in Simulink. The characteristics of arrays and cell in nominal condition- $T_{0}=25 C^{0}, G_{0}=1000 \mathrm{wm}^{2}$-are listed in tables (1) and (2). Moreover in this condition we should consider $R_{S}\left(G_{0}, T_{0}\right)=2.5 \Omega \mathrm{Cm}^{2}, R_{P}\left(T_{0}\right)=6005 \Omega \mathrm{Cm}^{2}$.

Table. 1. Array model parameters

\begin{tabular}{|l|l|}
\hline \multicolumn{2}{|l|}{ Characteristic of modelled array } \\
\hline Maximum power of module $P_{\max }$ & $200 \mathrm{~W}$ \\
\hline Corresponding voltage of $V_{\max }$ & $40 \mathrm{~V}$ \\
\hline Corresponding current of $I_{\max }$ & $5 \mathrm{~A}$ \\
\hline Open circuit voltage & $47.8 \mathrm{~V}$ \\
\hline Short circuit current & $5.4 \mathrm{~A}$ \\
\hline Open circuit radiation factor $C_{\mathrm{r}}$ & $6.3 \mathrm{C}$ \\
\hline Open circuit temperature factor $C_{\mathrm{t}}$ & 136.8 \\
\hline Short circuit temperature factor $I_{\mathrm{t}}$ & 2.2 \\
\hline weight & $6 \mathrm{~kg}$ \\
\hline Module dimensions & $1559 \mathrm{~mm} * 798 \mathrm{~mm}$ \\
\hline Number of cells in a string & 36 \\
\hline
\end{tabular}

\subsection{Characteristics of Modeled Solar Array in STP condition}

Performance of a module or other PV tool is evaluated in a certain condition which means that data given data by manufacturer is valid in those conditions named nominal conditions.

Table. 2. Standard and Nominal conditions used for PV

\begin{tabular}{|c|c|}
\hline Nominal condition & Standard condition \\
\hline $\begin{array}{l}G_{0}=800 \frac{\mathrm{W}}{\mathrm{m}^{2}} \\
\text { Radiation: }\end{array}$ & Radiation: $1000 \frac{W}{m^{2}}$ \\
\hline Temperature: $20 C^{0}$ & PV cell temperature: $20 C^{0}$ \\
\hline
\end{tabular}
modules testing

\subsection{PV Array Model}

PV array simulations in steady state condition are as below:
- All modules used in the array are the same and from identical manufacturer. Because in different cases each would have unique V-I curve, so they would have different voltage and current that leads to unbalance and returning current in arrays even in same radiation. Thereby, as possible all modules would be same in an array.

- Solar radiation is the same on all modules. In case of transient conditions there might be unbalance in modules currents and also module absorbs current acting as a load due to shadowing or malfunctioning of them. Usually this condition is avoided by placing a freewheeling diode. In case that the weather is cloudy by a cloud all of modules are in shadows. So in a cloudy weather there is no unbalance in current.

Considering those two assumptions in modeling, it is concluded that in steady state condition, usually currents of arrays strings are the same because voltage and currents of balanced modules are the same due to approximately same voltage of modules. Arrays voltage is sum of modules in branch voltages. In steady state condition PV arrays could be simulated by Eqs. 9 and 10 .

$$
I^{A}=M_{P} I^{M}
$$

$V^{A}=M_{S} V^{M}$

where, $V^{A}, I^{A}, M_{P}$ and $M_{S}$ represents arrays voltage, current, number of shunt branches and number of series PV modules.

\section{MPPT Concept and Its Equations}

A control system of PV is a maximum power point tracking system which results in obtaining maximum power in different weather condition by module. Since a PV system requires higher initial cost with respect to conventional powerhouse, it must obtain maximum power out of the sun [20]. MPPT is an electronic system that drives PV module so that makes module to generate maximum possible power. Using $\mathrm{P}-\mathrm{V}$ curve it is possible to find MPP point and thereby voltage and current of MPP point. Fig. 3 shows V-I characteristic of PV module.

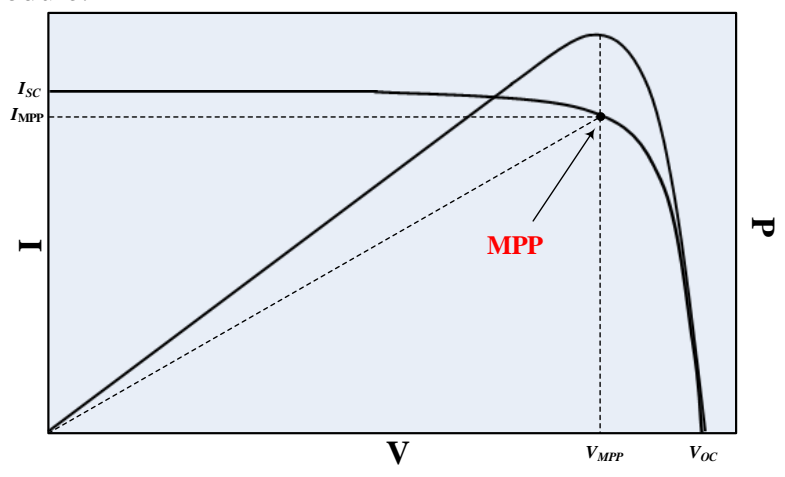

Fig. 3. V-I and P-V curves and MPP point of a PV module 


\subsection{Effect of Changing Sun Radiation}

In this section, $\mathrm{V}-\mathrm{I}$ and $\mathrm{P}-\mathrm{V}$ characteristic curve for different values of radiation will be drew. Note that all of curves drew in $25 C^{0}$ temperature. As it is clear from Figs. 4 and 5 , increase in solar radiation will lead to higher short circuit and higher open circuit voltage.

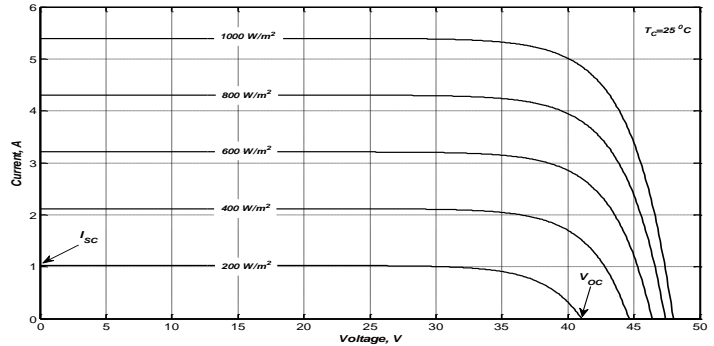

Fig. 4.V-I curve for different values of radiation

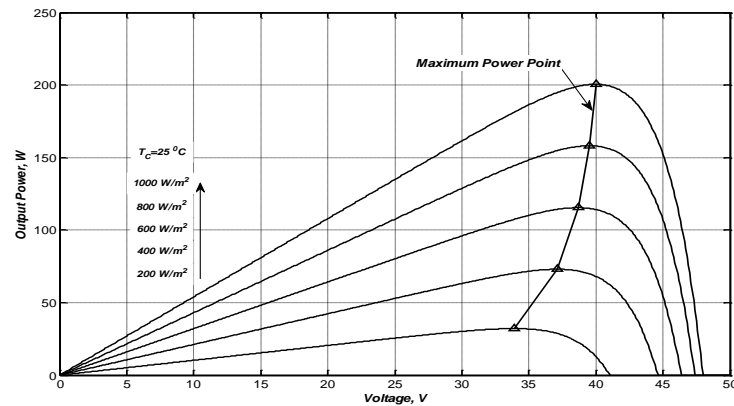

Fig. 5. P-V curve for different values of radiation

\subsection{Effect of Temperature Change on Its Performance}

The effect of temperature change is presented in Figs. 6 and 7. It is obvious that in lower temperature, maximum power and open circuit voltage is higher. On the other hand, temperature variation slightly lowers the short circuit current. All of these notes are presented in second section. And here, validity of the model could be realized.

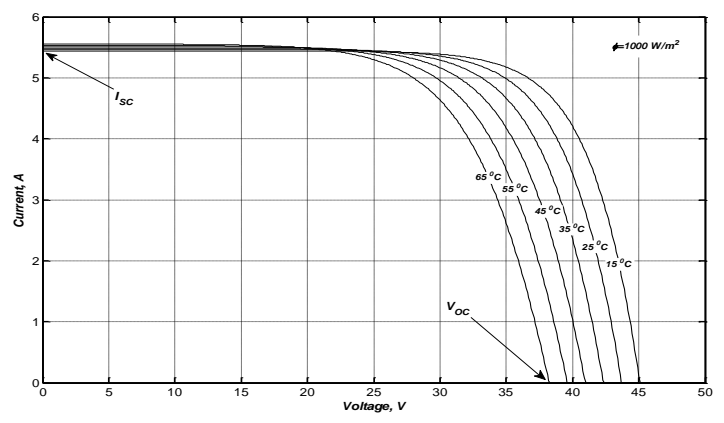

Fig. 6. V-I curve for same radiation and different operating temperatures of cell

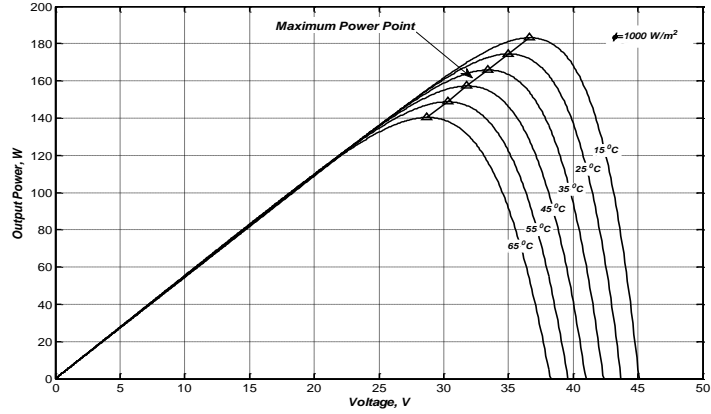

Fig. 7. P-V curve for same radiation and different operating temperatures of cell

\subsection{Intermediary Power Electronic Circuits}

Intermediary power electronic circuit is an electrical part of hybrid system like one is analysed in this paper. Since there are efficient inverters, by boosting output voltage of DC-DC converter to aircrafts DC voltage level, it is possible to connect it to aircrafts DC bus and other stages of reducing voltage would be accomplished by aircrafts electrical system.

\section{DC-DC Converter in PV system}

Tracking MPPT point is an inherent role of these converters, so it is necessary to add a resistance to converters output so that MPP could be obtained via Eq. (11).

$\frac{V_{M P P}}{I_{M P P}}=R_{D C-D C}^{i n}$

Advantages of this converter in solar applications include: Economically speaking, it tracks MPP point properly and increases the DC voltage level. As it is shown in figure, a DC-DC converter utilized which its output is connected to aircrafts essential bus. This converter plays two important roles in this study.

- Tracking MPP point: it alerts input resistance of converter so that it becomes equal to MPP resistance. $R_{M P P}$ is calculated by $R_{M P P}=\frac{V_{M P P}}{I_{M P P}}$.

- Boosting voltage level up to desired value for inverters input.

Regarding these notes, boost converter used because:

1. It is the best converter for boosting the voltages.

2. Its characteristics are so that it tracks MPP properly.

3. It is more economically.

In this converter, the output voltage is higher than input voltage; so it is called boost converter. Eq. (12) represents the relation between output and input voltage.

$\frac{V_{\text {output }}}{V_{\text {input }}}=\frac{1}{1-D}$

In a boost converter, and appropriate switching element is used which is usually an IGBT that could toggle 
rapidly. Fig. 8 shows a boost converter, its controller and pulse generator.

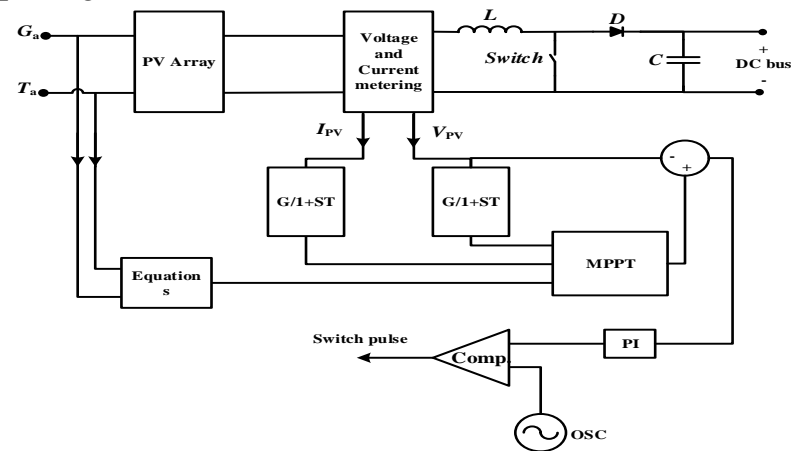

Fig.8. Schematic of a boost converter and its MPPT controller

This circuit has two operational stages:

- When IGBT turns on at $t=0$, current flows from source to inductance and switch. So energy will be stored in inductance.

- When IGBT turns off at $t=t_{1}$. So, inductors current flow in inductor, diode, capacitor and diode. Inductors current decreases when switch toggles its state. In this interval stored energy in inductor passes to load.

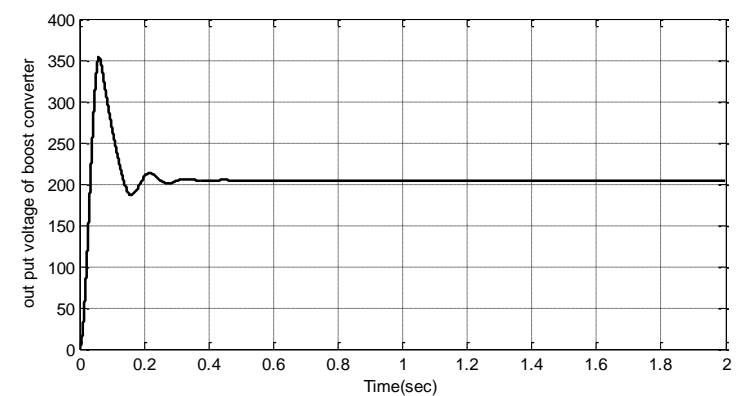

Fig. 9. Boost converter output voltage considering MPPT

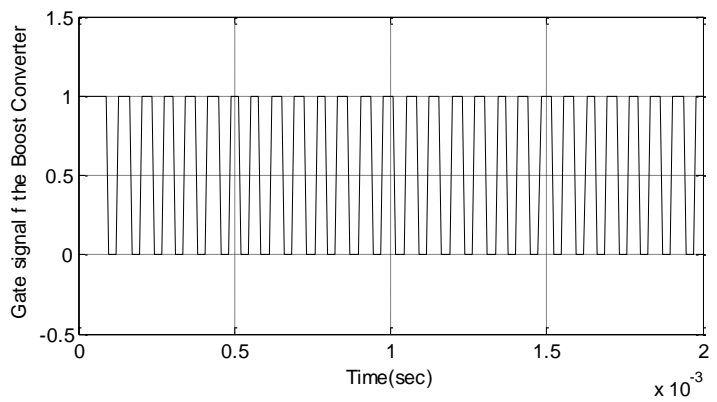

Fig. 10. Applied signal to IGBT

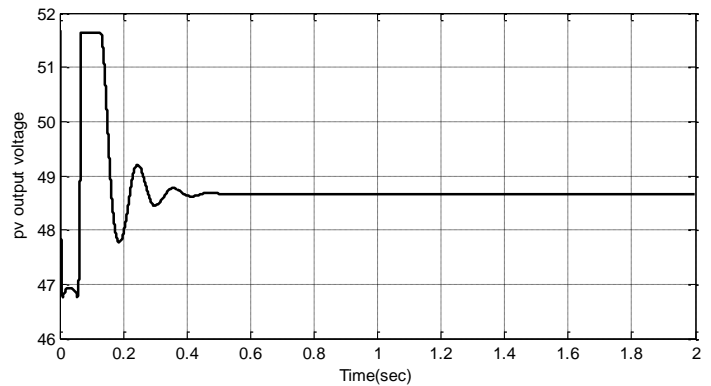

Fig.11. Solar modules output voltage considering transient states
Figs. 9-11 show output voltage of converter, gate signal of IGBT and solar module voltage, respectively. In this study, two series PV module where 36 modules in each one is used in form of $12 * 3$ array on wings of airplane.

Abstract and Keywords

The abstract is to be in fully-justified italicized text, below the author information. Use the word "Abstract" as the title, in 13-point Times New Roman, boldface type, initially capitalized ("Heading $0 "$ style). The abstract is to be in 10-point, single-spaced type, and boldface type ("Abstract" style for $1^{\text {st }}$ paragraph, and "Abstract2" for the $2^{\text {nd }}$ one). Use the same styles for Keywords.

\section{Control strategy}

In DC-DC converters, since the aim is to regulate output voltage, PI controller is most appropriate one. There are two control variables including $m_{a}$ modulation index and $\delta$ angle.

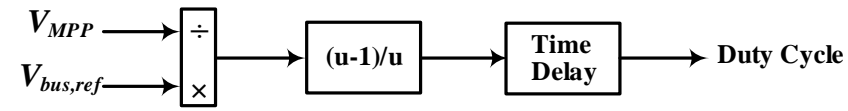

Fig.12. PV array and its equipments and method of connecting to Grid

Fig. 12 shows controlling process for desired controls. To alter inverters output voltage, DC buses voltage should be varied. So by knowledge of inverters output voltage, DC buses voltage should be alerted leading to constant output voltage. In this study $V_{\text {rms(inverter) }}=200 \mathrm{~V}$. So, DC buses voltage should not be lower than:

$V_{a b 1}=\frac{4}{\pi} \sqrt{3} \frac{V_{S}}{2}$

In that equation $V_{\mathrm{s}}$ and $V_{\mathrm{ab} 1}$ represent DC bust voltage and peak value of lines fundamental respectively. The regulated voltage of DC bus is $200 \mathrm{~V}$. To generate gate pulses, PWM technique is utilized. The saw tooth signal frequency is $10 \mathrm{kHz}$. Finally this blocks output is used to control the DC-DC converter. Two duty cycle calculator and pulse generator block play actuator role in this closed loop. Considering descriptions mentioned about using DC-DC and DC-AC converters in PV arrays, it is easy to understand the performance of converters to stay in MPP of array. Input voltage is set to maximum power point via DC-DC converter. Moreover, DC-DC converters input power is set to MPP of array via inverters controller. So, input resistance of DC-DC converter should always be in a value proper to MPP. Fig. 13 shows utilized converter performance in tracking MPP.

In initial points, since output voltage of DC-DC converter has ripple while input voltage is ripple-free, converter current has ripple. Thereby calculated resistance has ripple.

Since the efficiency is $\frac{P_{\text {out }}}{P_{\text {in }}}$, and there is ripple in output voltage in initial times, efficiency becomes more than $\% 100$. Fig. 14 shows IGBT duty cycle. As it is obvious, the ripple signal is due to converter output voltage and 
closed loop feedback. The maximum value for duty is calculated through input and output voltage.

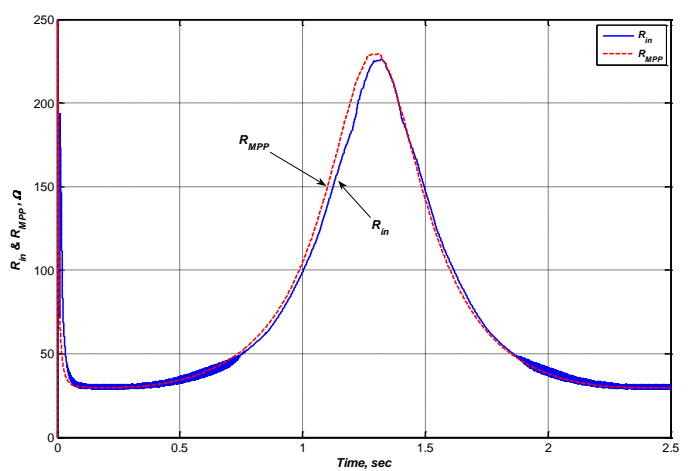

Fig. 13. Input resistance of DC-DC converter and resistance corresponding to MPP

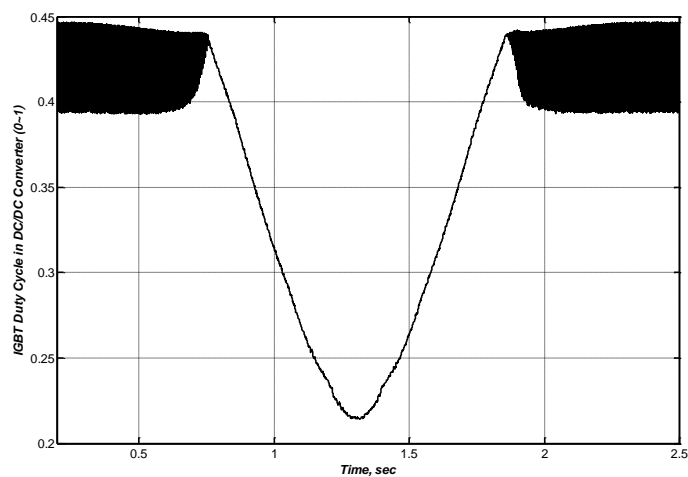

Fig.14. Duty cycle of IGBT switch due to solar radiation change

\section{Hercules Aircrafts Electrical System}

Hercules aircraft has 4 engines which each of them is connected to a generator via a Constant Speed Drive (CSD). Armature winding should rotate 6000 turns per minute, so gearbox converts motors constant speed (which is 13000 turns per minute) to generators nominal speed (which is 6000 turns per minute). The generator has 8 poles and in nominal speed generates $400 \mathrm{kHz}$ voltage [21]. The frequency of generated voltage is calculated in below equations:

$$
\begin{aligned}
& \text { Frequency }=\frac{\text { Number of poles } \times \text { R.P.M }}{60 \times 2} \\
& \text { Engine }- \text { Generator }=\frac{8 \times 6001}{60 \times 2}=400 \mathrm{~Hz} \\
& \text { ATM Frequency }=\frac{8 \times 6001}{60 \times 2}=400 \mathrm{~Hz}
\end{aligned}
$$

Generated voltages are $\mathrm{AC}$ and three phases with positive sequences. Output of each generator is connected to distribution system via three phases cables; and aircrafts' trunk is its grounding point. Phase and line output voltage is $115 \mathrm{~V}$ and $200 \mathrm{~V}$ respectively. Frequency margin of output voltage is between $380-420 \mathrm{~Hz}$. Fifth generator is APU generator with small generator high speed and half power. So that its start-up is subjected to wind suction out of the aircraft and will generate electrical energy in emergent cases. This generator is sensitive to temperature rise way that its output is reduced to half in ground compared to height (which cooling procedure is desirable there). Nominal power of 4 same generator and APU is $40 \mathrm{KVA}$ and $30 \mathrm{KVA}$, respectively. First moment, to start airplane, it is necessary to utilize an external source which could be either AC or DC because of high initial start-up current which cannot produced by airplane [22]. External source is either AC (400 volts, $400 \mathrm{~Hz}$ ) or DC $(28 \mathrm{~V}, 400 \mathrm{~A})$ type. There is another supply source which its output is high speed air that is applied for mentioned wind turbine. Thereby initial demanded electrical power is generated. Electricity produced by 4 generator passes to 4 main $\mathrm{AC}$ buses named main bus, left hand bus, right hand bus and essential bus through relays. Then it is converted to DC voltage via transformer and rectifier units (TRU) and AC-DC converters in order to be used in aircrafts different parts. It should be noted that most of aircrafts equipments needs DC voltage that is generated via TRUs. Moreover, because of high importance of DC voltage, distribution system is divided to DC and AC section as shown in Fig. 15.

If there are two active generators due to other generators failure, these will supply voltage in all buses. But if there is only one active generator, relays would keep only essential loads by shedding other buses. In this case aircrafts hydraulic systems would fail and just some essential systems will remain which is a very dangerous situation. But in this study, this situation is considered rare and thereby omitted. Moreover, DC buses consist of 4 types including main, essential, isolated and battery bus. Main and essential bus is connected via a relay. This relay lets current to flow only from main bus to essential bus and the loop is closed considering ground.

Isolated and essential buses are connected via a similar relay and the current flow will be "from isolated bus to essential bus" and "two way paths" in flight condition and on ground condition respectively. Isolated bus is connected to battery bus through a switch when airplane is on ground - and engines are OFF- all of energy needed for airplane is supplied from battery, battery bus and isolated bus. During starting engines, battery bus disconnects and essential bus generates power (from external source) and supplies starters and other parts.

\subsection{Battery}

Batteries characteristics are $28 \mathrm{~V}$ and $31 \mathrm{~A}$ per hour. It is connected to battery bus directly. Then it is connected to isolated bus via reverse current relay and absorbs current during charging process 


\section{Proposed System}

The the electrical energy needed in start-up process should be generated by external source, which are found only in standard airports that is suitable for Hercules. Moreover their main maintenance costs are high. Important note is the ability of this airplane to land in dirt bands. So, in case of landing there, without presence of external source it couldn't start and fly again. One solution is carrying an external source and professional staff I each machine which boosts the cost and lowers the aircrafts performance. Other problem is the lack of essential electrical power in case of 3 engines failure which could lead to dangerous condition. Because of fore mentioned sakes, equipment of aircraft to an emergency electrical system necessary to boost the reliability. The proposed system includes solar cell which its modules are on airplanes body and they will be connected to essential DC bus through a DC-DC converter.

\section{Conclusion}

In this paper, a solar electrical system designed and evaluated. Implementing PV system on Hercules, can generate a part of aircrafts power. Simulations results show PV systems prosperous performance in spatial application without imposing more cost to the system. Including this system, reliability is increased and lots of obstacles could be overcome utilizing this system. The proposed PV system can connect to the essential DC bus and batteries to generate the necessary electrical power in emergency cases. In addition, it can replace with APU and external power unit which reduces system total weight and cost.

\section{References}

[1] FuSChillo, Nicholas; Gibson, Roy D.; VanBlaricon, O., "Packaging System for Extendable Solar Photovoltaic or Thermoelectric Arrays," IEEE Transactions on Aerospace, vol.AS3, no.2, pp.76-80, 1965.

[2] Woods, L.M.; Ribelin, R.; Armstrong, J.H., "Next-Generation Thin-Film Photovoltaics," IEEE Aerospace and Electronic Systems Magazine, vol.22, no.10, pp.20-24, 2007.

[3] Roman, E.; Alonso, R.; Ibanez, P.; Elorduizapatarietxe, S.; Goitia, D.; , "Intelligent PV Module for Grid-Connected PV Systems," IEEE Transactions on Industrial Electronics, Vol.53, No.4, pp.1066-1073, 2006.

[4] Radmanesh H, Sharifi R, Radmanesh A, Fathi H. Novel Auxiliary Power Unit Configuration Based On Fuel Cell Technology for Civil Aircraft Application. Journal of Iranian Association of Electrical and Electronics Engineers. 2018; 14 (4) :89-94

[5] Khoobroo A, Fahimi B. On the Efficiency of the Fuel Cell Vehicles with Onboard Hydrogen Generation. Journal of Iranian Association of
Electrical and Electronics Engineers. 2008; 5 (2) :21-30.

[6] Chiang, S.J.; Hsin-Jang Shieh; Ming-Chieh Chen; , "Modeling and Control of PV Charger System With SEPIC Converter," IEEE Transactions on Industrial Electronics, Vol.56, No.11, pp.43444353, 2009.

[7] Lijun Gao; Dougal, R.A.; Shengyi Liu; Iotova, A.P.; , "Parallel-Connected Solar PV System to Address Partial and Rapidly Fluctuating Shadow Conditions," IEEE Transactions on Industrial Electronics, Vol.56, No.5, pp.1548-1556, 2009.

[8] Ali Asghar Ghadimi 'Hassan Rastegar 'Ali Keyhani, " Development of Average Model for Control of a Full Bridge PWM DC-DC Converter,", Journal Of Iranian Association Of Electrical And Electronics Engineers, Vol.4, No.2, pp.52-59, 2009.

[9] Velasco-Quesada, G.; Guinjoan-Gispert, F.; Pique-Lopez, R.; Roman-Lumbreras, M.; ConesaRoca, A.; , "Electrical PV Array Reconfiguration Strategy for Energy Extraction Improvement in Grid-Connected PV Systems,", IEEE Transactions on Industrial Electronics, Vol.56, No.11, pp.43194331, 2009.

[10] Velasco-Quesada, G.; Guinjoan-Gispert, F.; Pique-Lopez, R.; Roman-Lumbreras, M.; ConesaRoca, A.; , "Electrical PV Array Reconfiguration Strategy for Energy Extraction Improvement in Grid-Connected PV Systems,", IEEE Transactions on Industrial Electronics, Vol.56, No.11, pp.43194331, 2009.

[11] Paraskevadaki, E.V.; Papathanassiou, S.A.; , "Evaluation of MPP Voltage and Power of mc-Si PV Modules in Partial Shading Conditions,", IEEE Transactions on Energy Conversion, Vol.26, No.3, pp.923-932, 2011.

[12] Al-Sabounchi, A; Gow, J.; Al-Akaidi, M., "Simple procedure for optimal sizing and location of a single photovoltaic generator on radial distribution feeder," IET Renewable Power Generation, vol.8, no.2, pp.160-170, 2014.

[13] Ye Zhao; de Palma, J.; Mosesian, J.; Lyons, R.; Lehman, B., "Line-Line Fault Analysis and Protection Challenges in Solar Photovoltaic Arrays," IEEE Transactions on Industrial Electronics, vol.60, no.9, pp.3784-3795, 2013.

[14] E. Babaei ‘S. H. Hosseini ‘G. B. Gharehpetian, " Three-Phase to Single-Phase Matrix Converters: New Topology Based on New Control Method," Journal Of Iranian Association Of Electrical And Electronics Engineers, vol.10, no.2, pp.37-48, 2013.

[15] Alizadeh Shabestary S M, Saeedmanesh M, Rahimi-Kian A, Jalalabadi E. Real-Time Frequency and Voltage Control of an Islanded Mode Microgrid. Journal of Iranian Association of Electrical and Electronics Engineers. 2016; 12 (3) :9-14.

[16] Barreiro, C.; Jansson, P.M.; Thompson, A.; Schmalzel, J.L.; , "PV by-pass diode performance in landscape and portrait modalities," 37th IEEE 
Photovoltaic Specialists Conference (PVSC), pp.003097-003102, 2011.

[17] KOUTROULIS, E.; Blaabjerg, F.; , "Design Optimization of Transformer less Grid-Connected PV Inverters Including Reliability,", TwentySeventh Annual IEEE Applied Power Electronics Conference and Exposition, pp. 1959 - 1966, 2012.

[18] Soheil Mohamad Alizadeh Shabestary, Mohammadreza Saeedmanesh, Ashkan RahimiKian, Esmaeil Jalalabadi, "Real-Time Frequency and Voltage Control of an Islanded Mode Microgrid," Journal Of Iranian Association Of Electrical And Electronics Engineers, vol.12, no.3, pp.9-14, 2015.

[19] Gadelovits, S.; Sitbon, M.; Kuperman, A, "Rapid Prototyping of a Low-Cost Solar Array Simulator Using an Off-the-Shelf DC Power Supply," IEEE Transactions on Power Electronics, vol.29, no.10, pp.5278-5284, 2014.

[20] Feng Wang; Xinke Wu; Lee, F.C.; Zijian Wang; Pengju Kong; Fang Zhuo, "Analysis of Unified Output MPPT Control in Subpanel PV Converter System," IEEE Transactions on Power Electronics, vol.29, no.3, pp.1275-1284, 2014.

[21] Chappuis, C. K.; Olmsted, Leonard M., "Basic Design Principles for A-C Electric-Power Systems in
Large Military Aircraft," Transactions of the American Institute of Electrical Engineers, vol.65, no.1, pp.12-17, 1946.

[22] Carlson, K. W.; Sherrard, E. S., "Distribution system reliability of 28 -volt D-C aircraft electric systems," Transactions of the American Institute of Electrical Engineers, Part II: Applications and Industry, vol.71, no.2, pp.113-117, 1952. 


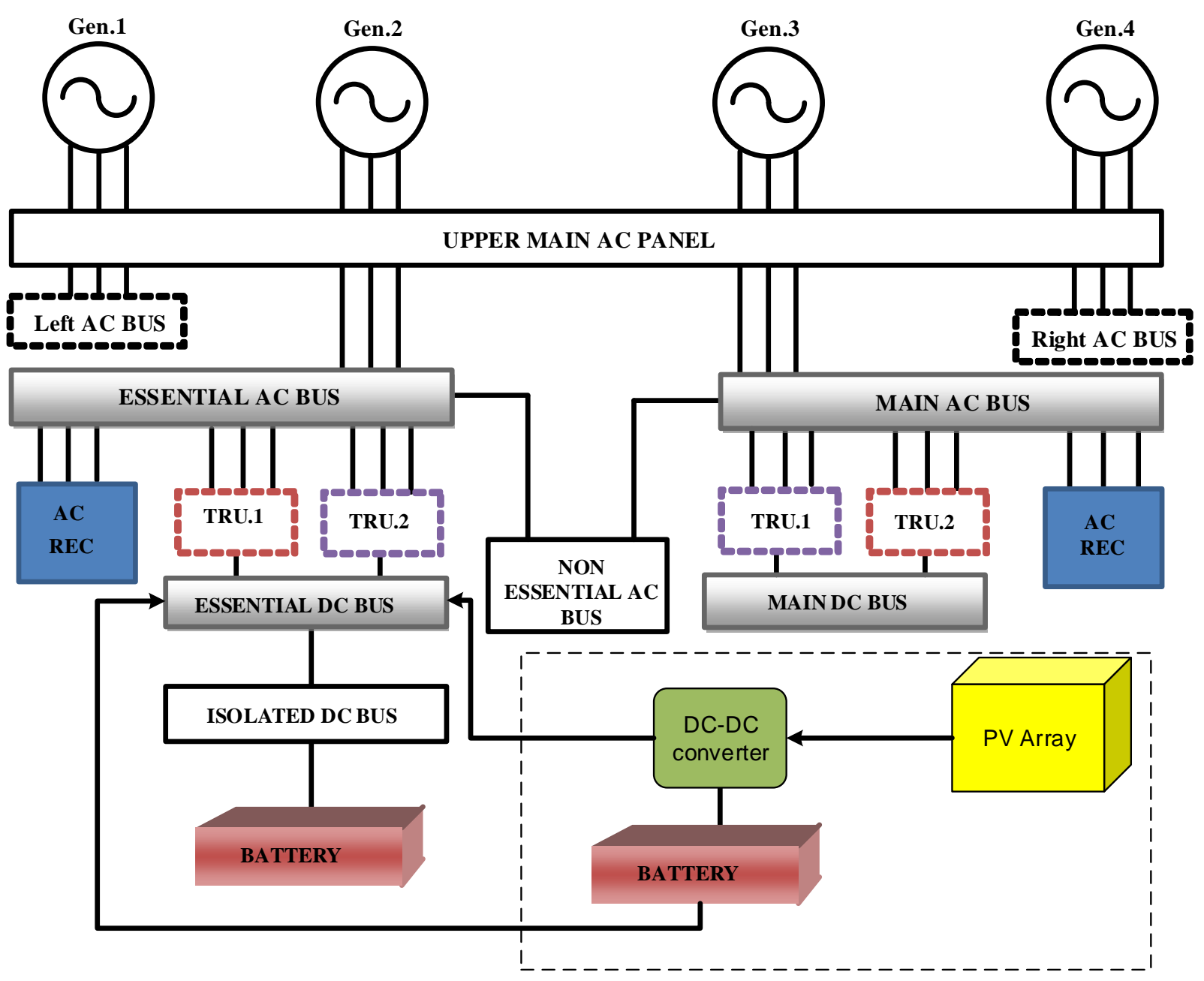

Proposed PV system

Fig.15. Main electrical energy distribution system in Hercules aircraft while PV block added to it 